Trinity University

Digital Commons @ Trinity

Psychology Faculty Research

Psychology Department

1986

\title{
Confusing Memories for Verbal and Nonverbal Communication
}

\author{
Paula T. Hertel \\ Trinity University, phertel@trinity.edu \\ Alice Narvaez \\ Trinity University
}

Follow this and additional works at: https://digitalcommons.trinity.edu/psych_faculty

Part of the Psychology Commons

Publication Details

Journal of Personality and Social Psychology: Attitudes and Social Cognition

\section{Repository Citation}

Hertel, P.T., \& Narvaez, A. (1986). Confusing memories for verbal and nonverbal communication. Journal of Personality and Social Psychology: Attitudes and Social Cognition, 50(3), 474-481. doi: 10.1037/ 0022-3514.50.3.474

This Article is brought to you for free and open access by the Psychology Department at Digital Commons @ Trinity. It has been accepted for inclusion in Psychology Faculty Research by an authorized administrator of Digital Commons@ Trinity. For more information, please contact jcostanz@trinity.edu. 


\title{
Confusing Memories for Verbal and Nonverbal Communication
}

\author{
Paula T. Hertel and Alice Narvaez \\ Trinity University
}

\begin{abstract}
Emotion portrayed nonverbally in videotaped conversations impaired memory for the specific meaning of utterances. Subjects produced more recognition (Experiment 1) or recall (Experiment 2) errors that were consistent with the emotional versions they had viewed than errors reflecting other emotions. In Experiment 1, this effect on recognition memory depended neither on the type of orienting task for nonverbal behaviors (attention to surface characteristics vs. interpretations) nor on the length of the retention interval. In Experiment 2, the number of emotional errors in recall was slightly dependent on the reported moods of the viewers. These and other outcomes sugeest that emotional interpretations of the nonverbal behaviors of others are associated in memory with the meaning of utterances. We discuss the results in reference to the effects of misleading information and to models of mood and memory.
\end{abstract}

An interviewer might note, we are warned, that the candidate who mumbles replies is lacking in confidence. Similarly, a therapist might observe that the crossed arms of a client indicate an unwillingness to be known. Popularized notions such as thesesome supported by research in nonverbal communication-imply that nonverbal behaviors are interpreted along emotional dimensions and that the behaviors and/or their interpretations are represented in memory. The purpose of the research we describe here was to discover if interpretations of emotion based on nonverbal behaviors influence memory for conversational utterances. A probable consequence of storing representations of these interpretations is that they will be available later, when someone is attempting to remember the content of a conversation. In trying to remember our conversations, then, our listeners may retrieve the emotion portrayed by our nonverbal behaviors, as well as the verbally expressed meaning of our utterances. Consequently, they may simply confuse what we have said with how we have said it.

The idea that people remember the emotional context of conversational utterances, perhaps to the detriment of memory for their individual meanings, is analogous to the well-established finding that people remember the meaning of sentences at the expense of remembering surface form (e.g., Sachs, 1967). In Sachs's experiment, for example, prose passages were followed by recognition items that either reproduced a passage sentence, changed the meaning of that sentence, or changed the surface form while preserving the meaning. Changes in meaning were

Experiment 1 was conducted as the second author's senior honors thesis. We are grateful to Susan Shackelford for assisting with data collection in Experiment 2 and to the drama and psychology students who directed and acted in the scenes, especially Andrea LeHaye and Barbara Spezia. Ralph Geiselman, Larry Jacoby, Marcia Johnson, and two anonymous reviewers provided very helpful comments on an earlier version of this article; we thank them.

Correspondence concerning this article should be addressed to Paula Hertel, Department of Psychology, Trinity University, 715 Stadium Drive, San Antonio, Texas 78284. recognized much more frequently than were changes in surface form.

In our view, investigating memory for sentences in the context of prose passages can be extended to investigating memory for sentences in the context of conversation, rich with added meanings from nonverbal behaviors. Now, if emotion depicted in conversation occupies a superordinate position with respect to individual sentence meaning (as does the gist of a passage), we should expect to find that changes in emotional meaning would be recognized more frequently than changes in wording that reflect the emotional meaning of the conversation, and that emotionally tinged elaborations are produced during recall.

Investigators report in the nonverbal communication literature that emotion can be recognized in facial expressions (e.g., Frijda, 1969), gestures (e.g., Gitin, 1970), posture (e.g., Rosenberg \& Langer, 1965), and tone of voice (e.g., Davitz, 1964; Kramer, 1963). Yet scant evidence can be found for confusions in memory for the content of verbal and nonverbal communication. Geiselman and his colleagues (Geiselman \& Bellezza, 1977; Geiselman \& Crawley, 1983) have interpreted incidental memory for the voice of the speaker from an interactive perspective. They suggest that connotations implied by vocal tone elaborate the meaning of spoken sentences. In contrast, we were interested in incidental memory for what was said and how it might be affected by such nonverbal factors as vocal tone (how it was said). Accordingly, we videotaped three scenes, each from two different emotional perspectives. Only the nonverbal behaviors varied between the versions of each scene and conformed to the emotions we wished to portray.

In Experiment 1, we examined confusions displayed in a forced-choice recognition task, following two types of orienting tasks that directed attention to nonverbal behaviors: a task that emphasized the surface characteristics of gestures and vocal tone and a task that encouraged interpretations of emotions. These tasks very roughly correspond to orienting tasks for verbal material that call attention to its surface features or to its meaning (cf. Craik\& Lockhart, 1972). Compared tosurface tasks, semantic tasks have more in common with the cognitive demands of recall 
and recognition and therefore produce better memory performance (Bransford, Franks, Morris, \& Stein, 1979). In borrowing this distinction, we intended to examine the necessary conditions for encoding meaning from nonverbal behaviors in such a way that it might be confused in memory with the meaning of dialogue. Is it necessary to consciously or effortfully interpret tone of voice and gestures-the whine and wringing of hands, for example-or is it sufficient merely to notice them while extracting meaning from dialogue? The conscious interpretation of emotion might be necessary to establish a record in memory that could be easily accessed during recall or recognition. On the other hand, encoding the meaning of dialogue is typically an effortless task, and it produces memories that are often easily retrieved. Perhaps we are equally skilled in extracting emotional meaning from nonverbal behaviors without intending to think about their significance.

In Experiment 1, then, subjects either attended to the surface characteristics of nonverbal behavior or interpreted the emotions they portrayed. Because Sachs (1967) found that confusions between semantically similar sentences increased with delay in testing, we wondered if confusions along an emotional dimension might also increase with time. So we varied the retention interval by testing immediately, or after one week. In printed recognition tests, ${ }^{1}$ we presented target utterances along with distractors that were emotionally consistent or inconsistent with the videotaped version, or emotionally irrelevant. In addition, we assessed recognition of the surface form of utterances by including surface distractors. A few studies suggest that memory for surface form in conversation is unusually good (e.g., Keenan, MacWhinney, \& Mayhew, 1977; Kintsch \& Bates, 1977) compared to memory for the surface form of written or spoken discourse (e.g., Sachs, 1967). A subsidiary aim, then, was to determine the possible influence of nonverbally portrayed emotion on recognition of surface form.

In Experiment 2, we employed cued-recall procedures in order to explore the relation between viewers' moods and their tendencies to erronoously remember emotion in utterances. Recent investigations of mood and memory (e.g., Boggiano \& Hertel, 1983; Bower, 1981; Isen, Shalker, Clark, \& Karp, 1978; Teasdale \& Fogarty, 1979) have indicated that errors in memory performance are qualitatively similar to the mood of the subject. Here, we were concerned with the possibility that the subjects' natural moods might either ameliorate or confuse the effects of actors' moods on memory for their utterances.

\section{Experiment 1}

\section{Method}

Materials. Each of three short scenes was videotaped twice, from two different emotional perspectives. The restaurant scene depicted a woman's reaction of disgust or interest in hearing her friend's tale of infidelity. In the classroom scene, a girl expressed joy or fear about going away to college to her friend across the aislc. And in the telephone scene, a woman expressed anger or distress in discovering that she had just been robbed. The two versions of each scene contained the same dialogue and differed only in the nonverbal behaviors of vocal tone, body posture, gestures, and facial expressions that the actors displayed.

In order to validate the two emotional perspectives, 12 pilot subjects saw one version of each scene or read written transcripts of the conversation. Their task was to pick from a list of adjectives (Plutchik, 1980, p. 166) five that seemed to best characterize the primary actor. Adjectives that were selected four or more times for any scene served as the criterion for evaluating perceived emotion. Subjects who saw Version 1 of the restaurant scene (disgust) chose annoyed, disgusted, displeased, and irritated. In contrast, the adjectives for those subjects who saw Version 2 (interest) were amused, curious, fascinated, and interested. For the classroom scene, subjects who saw Version 1 (joy) chose the adjectives delighted, elated, excited, happy, joyful, proud, and self-satisfied, whereas the adjectives anxious, confused, fearful, insecure, and nervous were selected by those who viewed Version 2 (fear). Finally, for Version 2 of the telephone scene (anger) the adjectives angr, annoyed, disgusted, irritated, and upset were chosen, whereas for Version 1 (distress), subjects chose the adjectives anxious, depressed, distressed, and upset. Individual subjects who read the written transcript of each scene made selections quite similar to those just described. However, as a group, their selections did not reflect the consistency of the results from the videotaped versions. For example, choices for the transcript of the restaurant scene included displeased as frequently as curious ( 3 subjects each).

In a second pilot task, subjects used a 7-point scale from not at all to extremely to respond to questions about the emotional state of the primary actor in each scene (e.g." "How fearful did the student seem about going away to college?"). The modian ratings by subjects who viewed the videotapes were consistent with the particular versions they had viewed (ie., close to not at all by those who saw the joy version, and close to extremely for those who saw the fear version). Median ratings by subjects who read the transcript were in the neutral range. This ordering of median ratings occurred for 10 of the 12 questions.

In Experiment 1, the forced-choice test for each scene consisted of six items containing four alternatives. The first two items were filler items. (Data for these items were not included in analyses.) The remaining four items contained the following altematives: the tanget (the actual utterance that occurred in the scene), a surface distractor (an utterance in which the exact wording of the target was changed, but the meaning was preserved), an emotional distractor (an utterance in which the surface form of the target remained mostly intact but the meaning was changed slightly by incorporating words or phrases that express emotion), and a surface/ emotional distractor (an utterance in which the previous surface and emotional distractors were combined). We included the last category to prevent subjects from adopting a test strategy of eliminating the one altersative out of the previous three that was most dissimilar. Hereafter; we refer to these last two categories of alternatives as emotional distractors.

The type of emotional distractors varied across items for all of the subjects. Two items contained distractors that reflected the emotion portrayed in Version 1 of the scenes, and two items reflected Version 2 (see Table 1 for examples). Thus, the recognition test presented two items with emotional distractors that were consistent with the version of the scene each subject had viewed and two items with emotional distractors that were inconsistent. ${ }^{2}$ Two forms of each test were constructed in order

\footnotetext{
${ }^{1}$ In constructing these tests, an important consideration was the difference between study and test modalities (audio/video vs. print). Perhaps a clearer demonstration of confusions would result from recognition alternatives presented in the audio or audio/video mode(s). However, in considering this procedure we were faced with the difficulty of holding voice tone, phrasing, and perhaps other nonverbal behaviors constant across target and distractors. Moreover, the inclusion of inconsistent emotional distractors seemed ludicrous (if nonverbal behaviors were held constant) or trivial (if they varied). And it seemed to us that tests for remembering in natural contexts would rarely take the form of instant replays.

${ }^{2}$ In onder to mask the nature of the experimental hypothesis, the first two items on the test (the filler items) included emotionally irrelevant distractors, rather than emotional distractors. In one item, for example, we changed 6 months to 8 months. In another item, we changed a name.
} 
Table I

Examples of Recognision Alsernasives

\begin{tabular}{ll}
\hline Type of distractor & \multicolumn{1}{c}{ Example } \\
\hline & \multicolumn{1}{c}{ Restaurant scene } \\
Target & I don't know. I wouldn't want to be in your position. \\
Surface distractor & I have no idea. I wouldn't want to be in your situation. \\
Disgust distractor & I don't know. I would never be in your position. \\
Surface/disgust & I have no idea. I would never be in your situation. \\
Interest distractor & I don't know. But I'd love to be in your position. \\
Surface/interest & I have no idea. But I'd love to be in your situation. \\
& \multicolumn{1}{c}{ Classroom scene } \\
& I think it's going to be a big change. It's so far away. I won't have my family around. \\
Target & I think it will be a big change. It's so far away. My family won't be around. \\
Surface distractor & I'm glad it's going to be a big change. It's very far away. I won't have my family around. \\
Joy distractor & I'm glad it will be a big change. It's very far away. My family won't be around. \\
Surface/joy & I'm afraid it's going to be a big change. It's too far away. I won't have my family around. \\
Fear distractor & I'm afraid it will be a big change. It's too far away. My family won't be around. \\
Surface/fear &
\end{tabular}

to vary the type of emotional distractor for each item. Across subjects, therefore, each taret was judged in the context of both types of emotional distractors. The order of the alternatives within each item was randomly assigned and was identical for both forms. Item order conformed to utcerance order in the scripts.

Design. A mixed design factorially combined three between-subjects factors (orienting task, retention interval, and version), with scene and type of emotional distractor (emotional allernatives that were either consistent or inconsistent with the version viewed) as vrithin-subjects factors. In the surface rask, the subjects recorded the frequencies of specific ges tures, wherens in the interpretation task the subjects rated discrepancies between vocal tone and posture in communicating attitude. The retenting interval was either approximately 5 min or 1 week. Half of the subjects saw Version 1 of all three scenes ("disgust" for the restaurant scene, "joy" for the classroom scene, and "distress" for the telephone scene); the other half saw Version 2 ("interest," "fea:", and "anger," respectivety). The order of the scenes ftelephone, restaurant, classroom; classroom, telephone, restaurant; or restaurant, classroom, telephone\} and che form of the recognition test were counterbalanced within conditions of orienting task, retention interval, and version.

Subjects. A totall of 105 undergraduate students at Trinity University volunteered as subjects in order to receive credit in an introductory psychology course. Groups of 3-5 subjects were randomly assigned to each of the eight combinations of orienting task, retention interval, and version. Three subjects failed to retum for the second session; so, in order to control for this self-selection factor and to establish appropriate counterbalancing, the data from 6 subjects were randomly eliminatod, with the constraint that no fewer than 12 subjects remained per condition and equal numbers saw the scenes in each order and took each form of the recognition test. The data from 96 subjects were analyzed.

Procedure. When subjects arrived for the first session of the experiment, the experimenter told them that they had volunteered for a pilot study on the social psycholagy of conversation. Then, the subjects in the surface-processing condition were told that the purpose of the study was to insure that three videotaped scenes contained an adequate number of noticeable body movements and to estimate vocal pitch. Their task was to focus on a specific body movement of the primary actor in each scene and to record is frequency (head nodding by the listener in the restaurant scene, hand movements by the student who got accepted to college, and eye movements in the telephone scene). Frequencies were recorded on paper, but subjects were required to keep their eyes on the videotape. Tbe experimenter encouraged them to listen to the conversation and mentioned that they would later rate their interest in each scene and write a short description of its sopic.
Following each scene, subjects rated the overall pitch of the primary actor's tone of voice from low (1) to high (7) and their interest in the scene from not at all interested (1) to very interested (7). Last, they wrote short descriptions of the scene's topic. The purpose of the interest-rating and clescribing tasks was to insure attention to the dialogue, in addition to the nonverbal behavious.

The subjects who were required to inter pret nonverbal behaviors were led to believe that the purpose of the pilot study was to investigate judgments about vocal tone and body posture. Their first task was to judge whether the primary actor's tone of voice fit with her body posture in communicating her attitude. This judgment was made on a scale that ranged from not discrepant (1) to discrepant (7). Then, a second task reauired that they choose five adjectives that described the primary actor's attitude as expresed by voca: tone and body posture only. Both tasks were designed to instigate careful ailention to the emotional meaning of norverbal behaviors, in contrast to the tasks of rating pitch and counting movements. These tasks followed the showing of each scene and were, in turn, followed by the interest-rating and description tasks.

After all of the tasks were completed, the experimenter dismissed the subjects who were to be tested one week later and told them that they would judge additional scenes when they returned. No mention of the memory test was made. The subjects who were tested in the first session were required to return in one week, but only to receive credit for their particjpation. ${ }^{3}$ Immediately prior to testing, all of the subjects were told that an additional purpose of the experiment was to examine memory for the dia:ogue. All of the recognition tests (one for each scone, taken consecutively) were self-paced, and their order conformed to the order in which the scerves had boen shown. Each test began with instructions to choose the alternatives that the subjects believed occurred in the videotape. Testing procedures were identical for both retention intervals.

\section{Results and Discussion}

Table 2 reports the mean proportion of choices for tangets, surfaco-form distractors, and emotional distractors in both testing conditions and according to the nature of the emotional distractors (consistent and inconsistent). Due to the lack of independence among these choices, the overall design was not submitted to analysis. However, it is quite clear that the proportion

\footnotetext{
${ }^{3}$ This procedure addressed the potential confound of self-selection in the delayed condition on the basis of rate of retum.
} 
Table 2

Mean Proporlion of Recognition Responses

\begin{tabular}{lccccc}
\hline & \multicolumn{3}{c}{ Type of emotional distractor } \\
\cline { 2 - 3 } \cline { 5 - 6 } \cline { 5 - 6 } Response choice & \multicolumn{2}{c}{ Consisient } & & \multicolumn{2}{c}{ Inconsistent } \\
\cline { 2 - 3 } \cline { 5 - 7 } Target & .59 & .46 & & .65 & .52 \\
Surface distractors & .20 & .23 & & .22 & .27 \\
Emotional distractors & .21 & .32 & & .13 & .20 \\
\hline
\end{tabular}

Note. $n=48$. The data are collapsed across the type of orienting task because it failed to produce reliable differences.

of target choices was larger than what one would expect from chance performance (.25), even afler one week. Again, conversation memory was unusually accurate (cf. Keenan et al., 1977; Kintsch \& Bates, 1977).

Separate analyses were performed for the number of emotional errors and the proportion of target choices when meaning was recossized (secognition of surface form). Following the suges tions of McCall and Appelbaum (1973), we employed a multivariate approach in evaluating effects involving the within-subjects factors and report approximate univariate Fs for Wilks's lambda criteria. Alpha was set at 05 for all analyses.

Emotional errors. In order to evaluate the number of emociomal errors in recognition memory, we performed a mixeddesign analysis of variance (ANOVA), with orienting task, retention interval, and version as between-subjects factors, and scene and the type of emotional distractor (consistent versus inconsistent) as within-subjects factors. First, the type of orienting task for nonverbal behaviors did not affect the number of emotional errors, either alone or interactively. This finding suggests that conscious attention to the emotional meaning of nonverbal behaviors was rot a necessary prerequisite for confusions and that merely attending to these bedsviors in the context of processing dialogue was sufficient,

Overall, more emotional errors occurred when the test was delayed than when it immediately followed the viewing $F(1$, $88)=12.78, M S_{e}=.367$. However, the length of the retention interval did not interact with other factors. Although the number of consistent emotional errors increased over the retention interval, for example, so did the number of inconsistent errors. Thus, our subjects tended to forget the meaning of utterances over time, but they were not increasingly influenced by the nonverbal context.

Most important, recognition of the correct meaning of utterances was affected by nonverbally communicated emotion. More emotional errors oocurred when the distractors were emotionally consistent than when they were inconcistent, $F(1,88)=18.43$, $M S_{e}=.295$. However, this effoct jointly depended on the particular scene and version on which the errors were based, $F=$ 4.36. Table 3 reports the mean number of consistent and inconsistent errors for each version of each scene. The three-way interaction of type, scene, and version was evaluated by examining the simple main effect of distractor type within each of the specific versions. Three versions (disgust, fear, distress) produced reliable differences between consistent and inconsistent errors (disgust, $\mathcal{H}(1,44)=4.98, M S_{e}=.706$; fear; $F(I, 44)=15.38, M S_{e}=.847$; listress, $F(1,44)=4.10, M S_{8}=.731$ ). Although the difference or the joy version was not statistically reliable, it was in the tppropriate direction.

These differences indicate that changes in emotional meaning were recognized more frequently than changes that preserve that meaning, but only under some conversational conditions. This restriction is not surprising if we consider the large number of actors that might operate in memory for conversations and the Jifficulty of holding them constant across our materials. One Jbvious factor is the match between recognition alternatives and Ictual interpretations of emotion portrayed in any particular rersion. Another factor, of course, is the ability of our actors to :xpress the desired emotions nonverbally. In particular, the subjects commented during their final debriefing that the woman in the telephone scene did not seem at all angry.

Finally, a reliable main effect of scene also oceurred, $F=4.16$, with the classroom scene producing the most errors.

Memory for sufface form. Because the large number of target choices showed that the surface for $m$ of the dialogue was well recognized, we wished first to determine the degree of surface memory, unencumbered by the influence of emotion, and then to determine if it had been affected by the type of emotion displayed nonverbalily or described by the emotional distractors. To obtain a measure of surface recognition that was independent of emotional confusions in memory, we determined the proportion of target choices out of semantically correct choices (target plus surface distractor) for each subject and then submitted these proportions to an ANOVA. The size of this proportion decreased over the retention interval, although not quive to chance levels of responding (immediate, .71; delayed, .60 ), $F(1,88)=11.41$, $M S_{\mathrm{e}}=.166$. In addition, the proportion of tarect choices varied across scenes, $F=8.70$. No other reliable difference was observed. Although we had suspected that memory for the surface form of utterances might be influenced by the type of emotional distractor (better without the distraction provided by emotionally consistent distractors), this was not the case.

\section{Experiment 2}

Mood effects in memory are oflen found with recall procedures but are rarely obtained in recognition (but see Leight \& Ellis, $198 \mathrm{l}$, for an exception). Therefore, we changed the testing procedure in Experiment 2 to cued recall in order to examine the

Table 3

Mean Number of Emotional Errors in Recognition

\begin{tabular}{ccc}
\hline & \multicolumn{2}{c}{ Type of emotional distractior } \\
\cline { 2 - 3 } Scene and version & Consistent & Inconsistent \\
\hline Restaurant & & \\
$\quad$ Version 1: Disgust & 0.48 & 0.21 \\
$\quad$ Version 2: Interest & 0.33 & 0.33 \\
Classroom & & \\
$\quad$ Version 1: Joy & 0.53 & 0.37 \\
$\quad$ Version 2: Fear & 0.77 & 0.25 \\
Telephome & & 0.35 \\
Version 1: Distress & 0.60 & 0.46 \\
Version 2: Anger & 0.46 & \\
\hline
\end{tabular}

Note, $n=48$. Two errors of each type were possible. 
possible interaction of subjects' and actors' moods in determining emotional errors in memory. We assessed moods at the start of the session with a mood checklist, presented in a deceptive fashion that, according to the subjects' reports, seemed believable. The experimenter told the subjects that the Psychology Department was interested in the moods of students who partiripate in ro search.

In addition to our interest in mood, we werc somewhat concerned that when we provided emotional recognition alternatives in the previous experiment we encouraged the subjects to make emotional errors that they might not have made without the emotional cues. Such cues were eliminated by our recall procedures.

The design of Experiment 2 also included a control condition in which subjects read transcripts of the scenes. The results of our pilot study indicated that subjects could infer emotional intent of the primary actors after reading transcripts of the scenes when they were asked to do so (although the nature of these inferences varied a great deal). This is not surprising, given that we wrote seenes that would lend themselves to interpretations consistent with the emotions we wished to vary. However, our interest in Experiment 2 was in whether these interpretations might occur spontaneously (unrequested) and affect recall in the same manner as emotion inferred from videotaped behaviors.

\section{Method}

At the beginning of the sessions, the experimenter distributed copies of a mood cliecklist. This cliecklist contained one of two randonly orderad lists of 21 emotional words, each followed by a 7-point rating scale anchored by not al all and extremely. The list was compiled by selecting the three most frequent descriptors used by pilot subjects for each veision of each scene and adding three additionlal words that were less frequently chosen (annoyed, disgusted. displeased, irrituted, amused, curious, interesiad, excited happy. joyful, confused. fearfiul, insecure, anxions. depressed, distressed, co(gr), upset, comfident, nervous, a)d tired). Subjocts were instructed to indicate their current movds under the cover that the psychology department was interested in the mood of subjects who participate in experiments. Then, the conversations from the previous experiment were presented in one of three cunditions: Version 1 of the three scenes, Verrion 2 of the threc scenes, or transcripts of the three seines. Eighteen subjects were randomly assigned to each condition. 'Three orders of the scenes were counterbalanced within these acquisition conditions. We instructed subjects in all conditions to read or to attend to the soenes; questions would folion. These brief instructions were used in order to make tbe instructions consistent across all versior.s, including the transcripts.

Following a 2-min interval, forms for the recall task were distributed. Four questions about the conversation in each scene wese listed on one page, in the order corresponding to comersational arder. (Examples are presen in the Appendix.) The instructions emphasized memory for utterances, rather than interpretations, but exact wording was not rouuirod. The subjects answered the questions for each scene in turn, with the order of the scenes preservel.

During debriefing, we solicited remarks about our attempts to deceive them about the pupose of the mood ratings, and we reauested written self-report on the judged source of emotion (verbal or nonvertbal) present in the scenes.

\section{Results and Discussion}

Emolional errors. Two judges, blind to acauisition conditions, independently categorized each response to each question as
Table 4

Mean Number of Emotional Errors in Cued Recall

\begin{tabular}{lccc}
\hline & \multicolumn{3}{c}{ Acquisition condition } \\
\cline { 2 - 4 } Scene and version & Version 1 & Version 2 & Transcript \\
\hline Restaurant & & & \\
Version 1: Disgust & 0.89 & 0.39 & 0.39 \\
$\quad$ Version 2: Interest & 0.00 & 0.28 & 0.39 \\
Classroom : & & & \\
Version 1: Joy & 1.1 I & 0.60 & 0.89 \\
Vession 2: Fear & 0.00 & 1.39 & 0.44 \\
\hline
\end{tabular}

Note. $n=18$.

containing no emotional errors or emotional errors reflecting either Version 1 or Version 2. Their judgments were based on deviations from the transcript that comesponded to each emotion partrayed on the videotape. (Comments about the mood of the actors were not considered to be emotional errors; they rarely occurred.) They disagreed about $4 \%$ of the responses, and then resolved those differences.

Table 4 presents the mean number of emotional errors of each type for each version of two scenes. (The results for the telephone scene are ignored inasmuch as very few emotional errors obtained, $M=.05$.) Most obviously, no emotional errors corresponding to the opposite version of the classroom scene were made by subjects who viewed the videotapes. This was also true for those who viewed Version 1 of the restaurant scene. Consequently, we analyzed the number of errors consistent with each version, comparing the videotape condition to the transcript condition. Subjects who viewed Version 1 of the restaurant scene (disgust) produced more emotional errors than did those who read the uranscript, $Y(1,51)=4.21, M S_{c}=.712$. Similarly, Version 2 of the classroom scene (fear) produced more errots than did the transcript, $F(1,34)=13.17, M S_{c}=.609$. Although the mean diference in errors consistent with Version I of the classroom scene (joy) was in the right direction (Version 1 vs. transcript), it was not reliable. Finally, the effect was not obtained for Version 2 of the restaurant scene (interest). In summary, all of the subjects who saw the videotapes produced more emotional errors that were consistent with the versions they had viewed than errors corresponding to the other versions. Morenver, for two types of emotional errors (disgust and fear) the videotapes produced reliably mare errors than did the transcripts. ${ }^{4}$

Recall accuracy. Our judges scored responses to each question for the number of propositions or idea units correctly recalled. ("I think it's going to be a big change" contains three propositions: (a) it will be a change, (b) the change is big, and (c) I think [that f and $b$ are true].) They disagread about $8 \%$ of the responses and resolved their differences. These numbers were then summod across all itcms in each scene and converled into a proportion of the total number of propositions in the scene. Table 5 reports the mean proportion of propositions recalled in each acquisition condition and scene. When these proportions were analyzed according to acquisition condition, scene, and version, we found

\footnotetext{
Also, note that subjects who read iranscripts made emotional errors that did not reliably differ according to the type of emotion.
} 
Table 5

Mean Proportion of Propositions Recalled

\begin{tabular}{ccc}
\hline & \multicolumn{2}{c}{ Scene } \\
\cline { 2 - 3 } Acquisition condition & Restaurant & Classroom \\
\hline Version 1 & .41 & .48 \\
Version 2 & .44 & .51 \\
Trenscript & .42 & .54 \\
\hline
\end{tabular}

Nore. $n=18$.

that they differed only with respect to sœene, $F=35.08$. The classroom scene was most accurately recalled, and it was also the scene that produced the most numerous emotional errors. (Similarly, the telephone scene produced the least accuracy, $M=$ .37 , and the fewest emotional errors.) Thus, based an analyses of average performance, emotional confusions did not depend on poor memory for actual dialogue. In addition, bivariate correlations between the proportion of propositions recalled and the numbcr of consistent emotional errors were not reliable. A negative relation between the number of emotional errors and the number of propositions correctly recalled by each subject would have suggested that subjects filled in the gaps in their memories for utterances with descriptions of nonverbally portrayed emotion. This was not the case.

Mood and emotional errors. Next, we examined the association of moods with corcesponding emotional errors in recall. In separate multiple regression analyses of errors correspoeding to each vession of the scenes (e.g., errors reflecting disgust, interest, joy, and fear), we added ratings on the mood scales after a contrast code representing the transcript condition versus the relevant videotape condicion. In predicting fearful errors, for example, the contrast code represented transcript versus Version 2. The mood scales we used in each analysis corresponded to the adjectives chosen by the pilot subjects for that version. For example, amused, curious, and inserested were used to predict the number of emotional errors corresponding to the interest version of the restaurant scene.

Four such analyses were performed, one for each type of emotional error for the restaurant and classroom scenes. I n only one case did the addition of the mood predictors reliably increase $\boldsymbol{R}^{2}$ over the variability due to viewing the videotape: When subjccts reported initial moods that were consistent with the fear version of the classroom scene, they tended to make more fearful errors in remembering that scese than could be predicted from knowledge that they had seen the fearful videotape, $F(3,30)=$ $3.48, M S_{\text {res }}=.182$. This .19 increase in $\boldsymbol{K}^{2}$ contributed to an $\boldsymbol{K}^{2}$ of .45 for the full equation, $F(4,29)=6.25, M S_{\text {res }}=.507$.

Therefore, we found limited relations amons moods reported at the start of the sessions and emotional errors in recall. ${ }^{\mathrm{s}}$ There are two possible reasons why these relations were so limited. First, in contrast to the designs of most research on mood and memory, we used reports of natural moods and thcreby limited the range of moods experienced by our subjects. Our subjects wcre not very insecure $(M=2.08)$ or distressed $(M=2.32)$, for example, but they tended to be interestod $(M=5.30)$ and curious $(M=5.45)$. Secood, only certain moods soemed to facilitate the interpretation of similar moods displayed by actors in our scenes (cf. Feshbach \& Feshbach, 1968). Of course, it is not surprising that the successful scene in this regard depicted fear about going away to college; most of our subjects were first-semester fireshmen.

In additional analyses of the mood data, we enterod the contrast codes that represented acquisition conditions into equations that included the appropriate mood predictors, in order to discover if moods accounted for the differences we had attributed to nonverbally communicated emotion. This use of mood covariates did not alter the previously described results.

\section{General Discussion}

In summary, we emphasize that we have found evidence for confusions in memory for what was said with how it was said, under a variety of processing and testing conditions, and that these confurions were independent of the viewers' moods. The effect of nonverbally communicatcot cmotion on memory for utterances was demonstrated for most of our materials. However, we cautiously note that the effect seems to depend on how convincingly the emotions are portrayed and how well the viewers can identify with the situations. Also, the effects we did obtain were modest; in Experiment I, for example, recognition of the surface form of utterances was quite good, even after a week's delay. We have orjanized our discussion of the major outcomes of thesc experiments in relation to (a) conditions for processing emotion from nonverbal behavior, (b) the effects of misleading information on memory, and (c) models of mood and memory.

Our results suggest that direcred interpretations of the emotional meaning of vocal tones and gesures are unnecessary in the production of later confusions in memory. Emotional errors occurred in a variety of conditions for processing nonverbal be haviors. In Experiment 1, the instructions that called attention to surface characteristics of nonverbal behaviors (number of gestures and vocal pitch) produved similar numbers of consistent emotional errors as did those that dernanded crnotional interpretations as part of the task. In Experiment 2, specific instrua tions regarding nonverbal behaviors were not provided. An interesting possibility, tben, is that interpretations of emotion automatically result from perceptions of nonverbal behavior. This possibility is consistent with the proposed biological basis for interpreting nonverbal behavior and findings that even very young children accurately identify emotion in facial expressions (lzard, 1971, 1978; Plutchik, 1980). However, this automaticity account is not demanded by our findings. It is quite possible that our subjects went beyond abe instrucrions for the surface task in Experiment 1 and the procesing task in Experiment 2 to consciously construct meaning from nonverbal expressions. Clearly, further research to address this issue of automaticity must include a measure of conscious interpretation.

The effects obtained in these experiments are sionilas to those obtained in studies of reconstructive memory as a function of misleading information (e.g., Hertel, 1982; Loftus, Miller, \& Burns, 1978; Spiro, 1980). However, the present experiments differ from these studies in our failure 10 find an increase over time in errors that reflect misleading information (nonverbally communicated emotion). The previous studies provided mis leading information temporally separate from the to-be-remem-

\footnotetext{
s Possible interactions between subject mood and version were also tested and found to be nonsignificant.
} 
bered event, but our misleading inf ormation was temporally integrated with utterances. Therefore, changes in discrimination based on temporal cues could at least partially account for the increased error rate in their studies, while failing to play a role in the present experiments.

An issue that is common among investigations of misleading information concerns the nature of its influence when memory for the original event is tested. Do errors reflecting misleading information (or nonverbally communicated emotion in this case) reflect integrative memory processes or do they merely show that the subject (a) has difficulty remembering the event, (b) remembers the postevent bias (or nonverbal behavior), and (c) uses the latter to fill in the gaps during recall? In such a case as the latter, as we discussed earlier, we might observe a negative relation between errors and accuracy; in Experiment 2, there was none. Another way to examine the possibility that subjects were confabulating is to ask them if they know that their emotional errors emanate from nonverbal expressions of meaning.

At the end of the session in Experiment 2, we asked subjects to indicate the nature of the emotion in each scene and whether it had been communicated verbally, nonverbally, or in both ways. Only 3 subjects attributed emotion to the nonverbal behaviors alone. ${ }^{6} \mathrm{Next}$, after telling them that emotions were communicated nonverbally, we asked subjects to judge whether these portrayals had affected their accuracy in recalling the utterances. They were allowed to review their protocols in making these judgments, and they indicated, to one degree or another, that they might have been influenced. However, no reliable correlations obtained between judged effecis of emotion and the number of emotionally consistent errors. These self-reports, then, provide some additional support for the notion that confusions resulted from integrative memory processes, rather than from conscious attempts to fill in the gaps in memory for dialogue.

Finally, we emphasize that models of mood and memory must address not only the influence of emotions experienced by the self, but the effects of emotions portrayed by others, as well. First, Experiment 2 provided evidence that moods reported by our subjects were correlated with recall errors that reflected fear or insecurity. Isen et al. (1978) and Bower (1981) have proposed models for understanding how the mood of the subject is related to qualitative aspects of memory performance, and our mood results are consistent with these explanations. However, by far the larger effects of emotions on memory performance in these studies were produced by the nonverbal behaviors of the actors, rather than by the moods of the audience. To account for these effects, models of mood and memory must provide for the activation of emotion in memory by events unrelated to the self.

Within Bower's (1981) model, for example, interpretations of emotions that have been nonverbally communicated would soem to occur via the links from evoking appraisals and expressive behaviors to the emotion node. Expressive behaviors (the way we display emotions) are, of course, what we refer to as nonverbal behaviors. Bower described evoking appraisals as "standard evocative situations which when appraised lead to [an emotion]" (p. 135). Our scenes, for example, represent situations that typically evoke one set of emotions or another, as indicated by pilot ratings. Perhaps through a process of identification with the actors, these situations evoke emotions, even though the viewers are not directly experiencing them. The classroom scene, par- ticularly the version representing fear, consistently produced emotional errors most frequently and, of course, going away to college is something that almost all of our subjects have experienced.

${ }^{6}$ Five out of 36 subjects for the restaurant scene and 18 out of 36 for the classroom scene attributed emotions to the verbal utterances alone.

\section{References}

Boggiano, A. K., \& Hertel, P. T. (1983). Bonuses and bribes: Mood effects in memory. Social Cognition, 2, 49-61.

Bower, G. H. (1981). Mood and memory. American Psychologist, 36. 129-148.

Bransford, J. D., Franks, J. J., Morris, C. D., \& Stein, B. S. (1979). Some general constraints on learning and memory research. In L. Cermak \& F. Craik (Eds.), Levels of processing in human memory (pp. 331354). Hillsdale, NJ: Erlbaum.

Craik, F. I. M., \& Lockhart, R. S. (1972). Levels of processing: A framework for memory research. Joumal of Verbal Leaming and Verbal Behavior, 11, 671-684.

Davitz, J. R. (1964). A review of research concerned with facial and vocal expressions of emotion. In J. R. Davitz (Ed.), The communication of emotional meaning (pp. 13-29). New York: McGraw-Hill.

Feshbach, S., \& Feshbach, N. (1968). Influence of the stimulus object upon complementary and supplementary projection of fear. Journal of Abnormal and Social Psychology, 66, 498-502.

Frijda, N. H. (1969). Recognition of emotion. In L. Berkowitz (Ed.), Advances in experimental sacial psychology IV (pp. 213-217). New York: Academic Press.

Geiselman, R. E., \& Belleza, F. S. (1977). Incidental retention of speaker's voice. Journal of Verbal Learning and Verbal Behavior, 5, 658-665.

Geiselman, R. E., \& Crawley, J. M. (1983). Incidental processing of speaker characteristics: Voice as connotative information. Journal of Verbal Learning and Verbal Behavior, 22, 15-23.

Gitin, S. R. (1970). A dimensional analysis of manual expression. Journal of Personality and Social Psychology, 15, 271-277.

Hertel, P. T. (1982). Remembering reactions and facts: The influence of subsequent infor mation. Journal of Experimental Psychology: Learning, Memory, and Cognition, 8, 513-529.

Isen, A. M., Shalker, T., Clark, M., \& Karp, L. (1978). Affect, accessibility of material in memory, and behavior: A cognitive loop? Journal of Personality and Social Psychology, 36, 1-12.

lzard, C. E. (1921). The face of emotion. New York: Appleton-CenturyCrofts.

Izard, C. E. (1978). On the ontogenesis of emotions and emotion-cognition relationships in infancy. In M. Lewis \& L. A. Rosenblum (Eds.), The development of affect (pp. 389-413). New York: Plenum.

Keenan, J. M., MacWhinney, B., \& Mayhew, D. (1977). Pragmatics in memory: A study of natural conversation. Journal of Verbal Learning and Verbal Behavior; 16, 549-560.

Kintsch, W, \& Bates, E. (1977). Recognition memory for statements from a classroom lecture. Journal of Experimental Psychology: Human Learning and Memory, 3, 150-159.

Kramer, E. (1963). Judgment of personal characteristics and emotions from nonverbal properties of speech. Psychological Bulletin, 60, 409.

Leight, K. A., \& Ellis, H. C. (1981). Emotional mood states, strategies, and state dependency in memory. Journal of Verbal Learning and Verbal Behavior; 20, 251-266.

Loftus, E. F., Miller, D. G., \& Burns, H. J. (1978). Semantic integration of verbal information into a visual memory. Journal of Experimental Psychology, 4, 19-31. 
MoCall, R. B., \& Appelbaum, M. I. (1973). Bias in the analysis of repeatedmeasures designs: Some alternative approaches. Child Development, 44, 401-415.

Plutchik, R. (1980). Emotion: A psychoevolutionary synthesis, New York: Harper \& Row.

Rosenberg, B. G., \& Langer, J. (1965). A study of postural-gestural communication. Journal of Personality and Social Psychology, 2, 593-597.
Sachs, J. (1967). Recognition memory for syntactic and semantic aspects of connected discourse. Perception and Psychophysics, 2, 437-444.

Spiro, R. J. (1980). Accommodative reconstruction in prose recall. Journal of Verbal Learning and Verbal Behavior; 19, 84-95.

Teasdale, J. D., \& Fogarty, S. J. (1979). Differential effects of induced mood on retrieval of pleasant and unpleasant events from episodic memory. Journal of Abnormal Psychology, 88, 248-257.

\section{Appendix}

\section{Questions for Cued Recall}

Instructions and questions for the restaurant and classroom scenes were as follows:

For each of the following questions, please try to recall the gist of the utterance, plus as much of the exact wording as you can remember.

\section{Restaurant Scene}

What did the listener in the restaurant scene say

1. When she first heard that David drove her friend home?

2. About her friend staying with David?

3. After her friend said that she had such a good time for the first time in months?
4. When asked if her friend should tell Joe about the night before?

\section{Classroom Scene}

What did the student who was accepted to State University say about

1. Leaving home to go to school?

2. The courses in college?

3. The sororities?

4. Living in the dorms?

Received May 24, 1985 